\title{
The Legacy of Raimond Castaing: A Perspective at 60 Years
}

\author{
P.K. Carpenter ${ }^{*}$, E.P. Vicenzi ${ }^{* *}$, R. Gauvin ${ }^{* * *}$, and J. Fournelle ${ }^{* * * *}$ \\ *Earth and Planetary Sciences, Washington University, St Louis, MO, 63130 \\ ${ }^{* *}$ Museum Conservation Institute, Smithsonian Institution, Suitland, MD 20746 \\ ${ }^{* * *}$ Dept. of Mining and Mineral Engineering, McGill University, Montreal, Quebec, H3A 2B2 \\ ${ }^{* * * *}$ Dept. of Geoscience, University of Wisconsin-Madison, 1215 W. Dayton St, Madison, WI 53706
}

Raimond Castaing is arguably the most influential individual in the field of x-ray and ion microanalysis (Figs. 1 and 2). In this paper we briefly summarize his remarkable contributions. Castaing's 1951 Ph.D. thesis and the English translation by Duwez and Wittry, "Application of Electron Probes to Local Chemical and Crystallographic Analysis", serve as an important treatise on the birth of electron-probe microanalysis (EPMA) [1,2].

Castaing adopted a novel approach by nondestructively performing quantitative analysis on micron-sized precipitates in metallurgical samples (previously identified only by powder x-ray diffraction). In doing so he developed the electron microprobe instrumentation, the wavelength-dispersive spectrometer (WDS), improved aspects of electron optics including aberration correction, developed the theory of quantitative analysis, and applied the technique to important problems of the day. After these impressive accomplishments he supervised the development of the ion microprobe with his then Ph.D. student Georges Slodzian. A number of his contributions to microanalysis are used either in essentially unmodified form or make up the foundation of modern theory of microanalysis.

The instrumentation he used consisted of a commercial electron column to which was added a WDS, a reflected light optical microscope, and a sample stage assembly with xyz motion. Instrumental developments were closely coupled with theoretical aspects of the probe-forming system, beam diameter as a function of probe current, and the correction of astigmatism. The electron column was modified in order to produce higher probe current necessary for x-ray microanalysis. These critical efforts by Castaing illustrate how the basic electron column required necessary improvements to achieve required performance. The importance of a co-axial reflected light microscope was emphasized and a similar system was developed for sample viewing and placement relative to the electron beam. Some instrumentation design aspects ultimately required commercial resources to improve optical microscope and WDS takeoff angle issues. A sample introduction and isolation design was developed and the issue of sample displacement resulting from variable vacuum was recognized. The small depth of field design of the optical microscope allowed location of the sample analysis z-axis position, ensuring X-ray optical focus in the WDS.

The effect of electron column design and parameters affecting beam diameter and stigmation were evaluated by Castaing. For this first instrument a high probe current was necessary, which required an assessment of the thermal effects of beam irradiation on samples. Experimental observations were compared to theoretical calculations concerning these factors. The need to have sufficient probe current and analytical spot size of $\sim 1$ micron remain a reference point in the thesis, as any relaxation in instrumental requirements would have failed to adequately solve the problem.

A WDS with Johannson geometry was built for x-ray diffraction, and used a quartz diffracting crystal with a Geiger counter for detection. The WDS alignment presented a significant challenge and a systematic procedure was outlined in order to iteratively locate the $\mathrm{Cu} \mathrm{K} \alpha$ peak excited from a $\mathrm{Cu}$ sample.

The theory of quantitative analysis included the relation between x-ray intensity and concentration, with both theoretical and experimental aspects discussed. Castaing recognized the need to correct for atomic number effects, $\mathrm{x}$-ray absorption, and characteristic x-ray fluorescence, thus laying the foundation for le- 
gions of scientists uttering the acronym "ZAF". While the theoretical understanding of electron and x-ray physics was generally incomplete at this time, Castaing exhibited remarkable insight to focus on problem solving. The central importance of the x-ray absorption correction and correction formulae were clear priorities, with the experimental determination of $f(\chi)$ and the relation of $f(\chi)$ to the extent of electron scattering in the sample. The theoretical basis and correction for characteristic x-ray fluorescence was discussed and compared with experimental results. An in-depth evaluation of characteristic fluorescence for $\mathrm{K} \alpha \mathrm{l}$ radiation was included as an appendix to the thesis. It was not until later that Castaing and Descamps performed tracer experiments to provide experimental $\Phi(\rho z)$ curves, which formed the basis for subsequent work on $\Phi(\rho z)$ correction algorithms [3].

In addition to construction of a ground-breaking instrument and thorough development of correction theory, Castaing also presented applications of EPMA. These included the characterization of a $\mathrm{Cu}-\mathrm{Zn}$ diffusion couple, analysis of $\mathrm{Al}_{2} \mathrm{Cu}$ inclusions, and microanalysis of phases in the $\mathrm{Cu}-\mathrm{Sb}$-Sn alloy system. Castaing also discussed crystallographic analysis via Kossel lines, which paved the way for the development of electron-backscatter diffraction (EBSD) and channeling analysis of materials.

Castaing was remarkably prescient and later engaged in important aspects of microanalysis such as light element analysis, x-ray mapping, and gun design, all of which continue to be important topics for both instrumentation and software development. His enduring contribution of EPMA has been utilized in many disciplines but is especially central to the earth and planetary sciences.

In recognition of his contributions, Castaing was awarded the Roebling Medal by the Mineralogical Society of America in 1977 (presented by Klaus Keil, a co-inventor of the energy-dispersive spectrometer) $[4,5]$. Several authors have celebrated the contributions of Castaing, and the reader will find of interest the papers from the 1999 Topical Session of the Microbeam Analysis Society entitled "Fifty Years of Electron Probe Microanalysis: A Celebration Honoring Raimond Castaing", published in the Journal of Microscopy and Microanalysis [5-7].

\section{References}

[1] Castaing R (1951) Application des sondes electronique a une methode d'analyse ponctuelle chimique et cristallographique. PhD Thesis, University of Paris, 1952, Publication ONERA No. 55

[2] Castaing, R. "Applications of Electron Probes to Local Chemical and Crystallographic Analysis". English translation: Duwez, P. and Wittry, D.B. Special Technical Report, Dept. of the Army, California Institute of Technology. Available from MAS web site:

http://www.microbeamanalysis.org/resources/Castaing-Thesis-optOCRreduced.pdf/view? searchterm $=$ None

[3] Castaing, R. and Descamps, J. (1955) J. Phys. Rad., 16, 304.

[4] Keil, K. (1977) Am. Min. 63, 601-602.

[5] Castaing, R. (1977) Am. Min. 63, 602-604.

[5] Duncumb, P. (1998) J. Anal. At. Spectrom., 1999, 14, 357-366.

[6] Grillon, F., and Philibert, J. (2002) Microchim. Acta. 138, 99-104.

[7] 1999 Topical Symposium of the Microbeam Analysis Society, in Micros. Microanal. V7, N2, pp 93219. 